\title{
Morphometric study regarding ophthalmic and internal carotid arteries utilizing computed tomography angiography
}

\author{
RADU ANDREI BAZ ${ }^{1,2}$, SANDA JURJA $^{3,4}$, RADU CIULUVICA $^{5 *}$, CRISTIAN SCHEAU $^{6 *}$ and RADU BAZ ${ }^{1,2}$ \\ ${ }^{1}$ Department of Radiology and Medical Imaging, Faculty of Medicine, 'Ovidius' University, \\ 900630 Constanta; ${ }^{2}$ Department of Radiology, 'Sf. Apostol Andrei' County Hospital, 900591 Constanta; \\ ${ }^{3}$ Department of Ophthalmology, Faculty of Medicine, 'Ovidius' University, 900470 Constanta; \\ ${ }^{4}$ Department of Ophthalmology, 'Sf. Apostol Andrei' County Hospital, 900591 Constanta; ${ }^{5}$ Department of Anatomy, \\ Faculty of Dental Medicine, 'Carol Davila' University of Medicine and Pharmacy; ${ }^{6}$ Department of Physiology, \\ 'Carol Davila' University of Medicine and Pharmacy, 050474 Bucharest, Romania
}

Received July 20, 2021; Accepted August 20, 2021

DOI: $10.3892 /$ etm.2021.11035

\begin{abstract}
The aim of the present study was to accurately measure the diameter of the ophthalmic artery (OA) and investigate whether bilateral variations in diameter can be recorded in relation to patient age and sex. A retrospective study including 80 computed tomography angiographic (CTA) examinations and a total of 160 arteries was conducted to demonstrate the morphometric aspects of the OAs analyzed bilaterally by CTA examinations, while considering the references of the internal carotid artery (ICA) caliber. Precise measurements performed on the OA and the ICA below and above the ophthalmic emergence revealed an OA diameter of $1.38 \pm 0.24 \mathrm{~mm}$ and a narrowing of the ICA between the origin of the OA of $1.5 \pm 0.25 \mathrm{~mm}$. Variations in the OA and the ICA calibers were studied in subjects with normal cervical vasculature on CTA. After a thorough statistical study, variations in OA and ICA caliber on each side were identified, between both sex and age-related groups, revealing morphometric parameters of the OA in relation to the ICA.
\end{abstract}

\section{Introduction}

The ophthalmic artery (OA) is the first intracranial collateral branch of the internal carotid artery (ICA). It originates immediately after the emergence of the ICA from the cavernous sinus, features a short intracranial course, follows the optic

Correspondence to: Professor Sanda Jurja, Department of Ophthalmology, Faculty of Medicine, 'Ovidius' University, 1 Universitatii Al., 900470 Constanta, Romania

E-mail: jurjasanda@yahoo.com

*Contributed equally

Key words: statistical study, anatomy, ophthalmic artery, internal carotid artery, computed tomography angiography canal, and enters the orbit (1). After entering the orbit it branches out in a complex pattern and vascularizes the eyeball and surrounding ophthalmic tissues, contributing indirectly to the neutralization of the toxic particles resulting from a high degree of exposure of the eye to external factors $(2,3)$. The ocular branches provide the blood supply to the optical apparatus and the orbital branches supply the ocular adnexa $(4,5)$.

According to the Bouthillier classification system, the OA is the ICA's fifth branch and belongs to its sixth segment. The ICA is divided into seven segments: cervical, petrous (emergence of caroticotympanic and vidian arteries), lacerum, cavernous (that provides the meningohypophyseal and inferolateral trunks), clinoid, ophthalmic (that gives rise to the OA and the superior hypophyseal artery), and communicating segment where before its final division, the ICA leads to the anterior choroidal and posterior communicating arteries (6).

The first orbital dissection was performed in the 19th century, in particular with the works of Meyer (7) who was the first anatomist who, based on macroscopic cadaveric dissection, assessed the normal orbital vascularization and described the anatomy and branching of the OA.

Due to the significance of OA, numerous authors have studied its distinct features, such as the caliber, course variants, distance between its entrance into the optic canal, and eyeball. An exhaustive study of the literature reveals a solid number of views held by various researchers, the OA being primarily studied on cadavers $(1,4,8,9)$ and classic angiographic studies $(10,11)$, in line with the tendency to study even smaller caliber vessels (12-14).

Although digital subtraction angiography (DSA) remains the gold standard for visualizing smaller vessels, it is an invasive diagnostic method with significant morbidity represented mainly by ischemic stroke due to the embolic phenomenon, especially in older patients with atherosclerotic vessels. Neurological complications may be reduced if arteriography were restricted to patients undergoing surgery (e.g., carotid endarterectomy) or if diagnostic angiography were replaced with a reliable non-invasive imaging modality (15). 
The growing clinical applications of computed tomography angiographic (CTA) can be attributed to the development of helical CT scanners with a larger number of detector rows. The increase in the number of image sections per study allows for the description of complex vascular axes with small branches and correct analysis of nearby soft tissues $(16,17)$.

The aim of the present study was to accurately measure the diameter of the $\mathrm{OA}$ and investigate whether bilateral variations in diameter can be recorded in relation to patient age and sex. The result showed that variations in OA and ICA caliber were identified for both sex and age.

\section{Patients and methods}

Patients and criteria. A retrospective study was conducted between 01.03.2017 and 01.03.2019, comprising 80 CTA investigations from patients aged between 22 and 80 (40 male and 40 female), totaling a number of 160 arteries. The patients were submitted to a CTA evaluation of the carotid artery at the attending physician's indication for various assessments in the context of their underlying disease. Prior informed consent was obtained from the patients. The research was conducted in accordance with the Helsinki Declaration and in compliance with all relevant national regulations regarding patient studies (approved by the Ethics Committee of 'Sf. Apostol Andrei' County Hospital, 34490/08.08.2019).

The inclusion criteria for the study were: CT confirmation of the ICA normal anatomy, more precisely, the absence of atheroma plaques or congenital or tumoral vascular pathologies affecting the carotid vascular axis, as well as the lack of carotid aneurysms, changes in vascular structure, or neoplasms affecting the ICA.

Method. CTAs were performed on a multi-slice CT scanner with 64 detectors (Light Speed VCT; GE Medical Systems). The actual scan was augmented by automatic intravenous injection of iodinated contrast material at a dose of $1 \mathrm{ml} / \mathrm{kg}$ body weight at an injection rate of $4 \mathrm{ml} / \mathrm{sec}$. The scan was started individually by tracking the loading bolus, with a region of interest placed at the aortic arch level and with automatic triggering at detected values of over 120 Hounsfield units. The obtained images were sent to a dedicated workstation (Advantage Workstation, GE Medical Systems) for post-processing. From the source images, volume rendering technique (VRT) reformatted images (Fig. 1) and multiplanar reconstructions (MPR), respectively, were obtained in the tri-planar system (axial, sagittal, and coronal), thus revealing the OA and its origin from the ICA. Maximum intensity projection (MIP) images were also employed. The OA was measured semi-automatically at its entrance in the optical canal, approximately $5 \mathrm{~mm}$ from its origin. The ICA was measured with the same tools caudally and cranially from the OA's origin.

The study aimed to measure the OA diameter accurately and investigate bilateral variations in diameter related to age and sex of the patients. The measurement of the OA's diameter at the point of interest was performed automatically (Fig. 2).

Once the OA was identified and measured, ICA measurements followed in the pre- and post-emergent portions of the
OA. Oblique MIP images were captured to highlight the ICA regions of interest, the level at which the measurements were performed automatically, similar to the previously presented method (Fig. 3).

The measurements were also shown axially to have greater ease in visualizing the regions of interest (Fig. 4). In all cases, the minimum diameter (Dmin) is presented, according to the automatic measurements.

The influence of age and sex was determined using the average diameter of the OA (average between the diameter on the left and right sides). The patients were stratified according to five age groups: <40 years, 40-49 years, 50-59 years, 60-69 years, and $>70$ years. The dimensions of the ICA were also measured before and after the emergence of the OA, and its variable relation to each part and the sex of the subjects were recorded.

Statistical analysis. The Student's t-test for two pairs of samples was used to investigate the differences in right and left diameters, a Welch t-test was used to determine the influence of sex on the diameter and to correlate these two factors, the point-biserial correlation coefficient test was utilized. To investigate the influence of the age group the ANOVA procedure was used, applying the Tukey-Kramer post-hoc test. The tests were considered statistically significant when the P-value was $<0.05$.

\section{Results}

Patients. The study subjects presented normal internal carotid arteries confirmed by CTA and each OA showed emergence from the ophthalmic segment of the ipsilateral ICA. CTA images of the ICA were processed and the OA was identified as originating along the ICA on MPR reconstructions and MIP images.

From the measurements performed, the results revealed an average diameter of the OA of $1.38 \mathrm{~mm}( \pm 0.23)$, with a median value of $1.35 \mathrm{~mm}$ (Table I).

OA caliber and sex. Following analysis of the study data, a slight sex-related difference was denoted between the diameters of the OA. In men, the mean average value was $1.43 \mathrm{~mm}$ $( \pm 0.24)$, while in women, the average value was $1.34 \mathrm{~mm}$ $( \pm 0.20)$ (Table II). Albeit a difference of approximately $0.1 \mathrm{~mm}$ was recorded in the caliber of the OA between the two groups; this did not prove to be statistically significant (P>0.05, Table III).

The dimensional variation of the entire group of patients in terms of OA diameters relative to the laterality was analyzed using a bidirectional Welch t-test. The results revealed no significant difference in our study group. The average value of the diameter on the right side was $1.38 \mathrm{~mm}$ $( \pm 0.24)$ with a median of $1.37 \mathrm{~mm}$, and on the left side, we found a value of $1.38 \mathrm{~mm}( \pm 0.23)$ with a median of $1.37 \mathrm{~mm}$. The values varied between 1.01 and $1.98 \mathrm{~mm}$ on the right side, respectively, and $1.03-1.95 \mathrm{~mm}$ on the left side at a P-value of 0.96 (Table I).

The values of the OA diameters were calculated for each sex and for each side. In the female group, an average diameter for the $\mathrm{OA}$ on the right side of $1.32 \mathrm{~mm}( \pm 0.22)$ was 

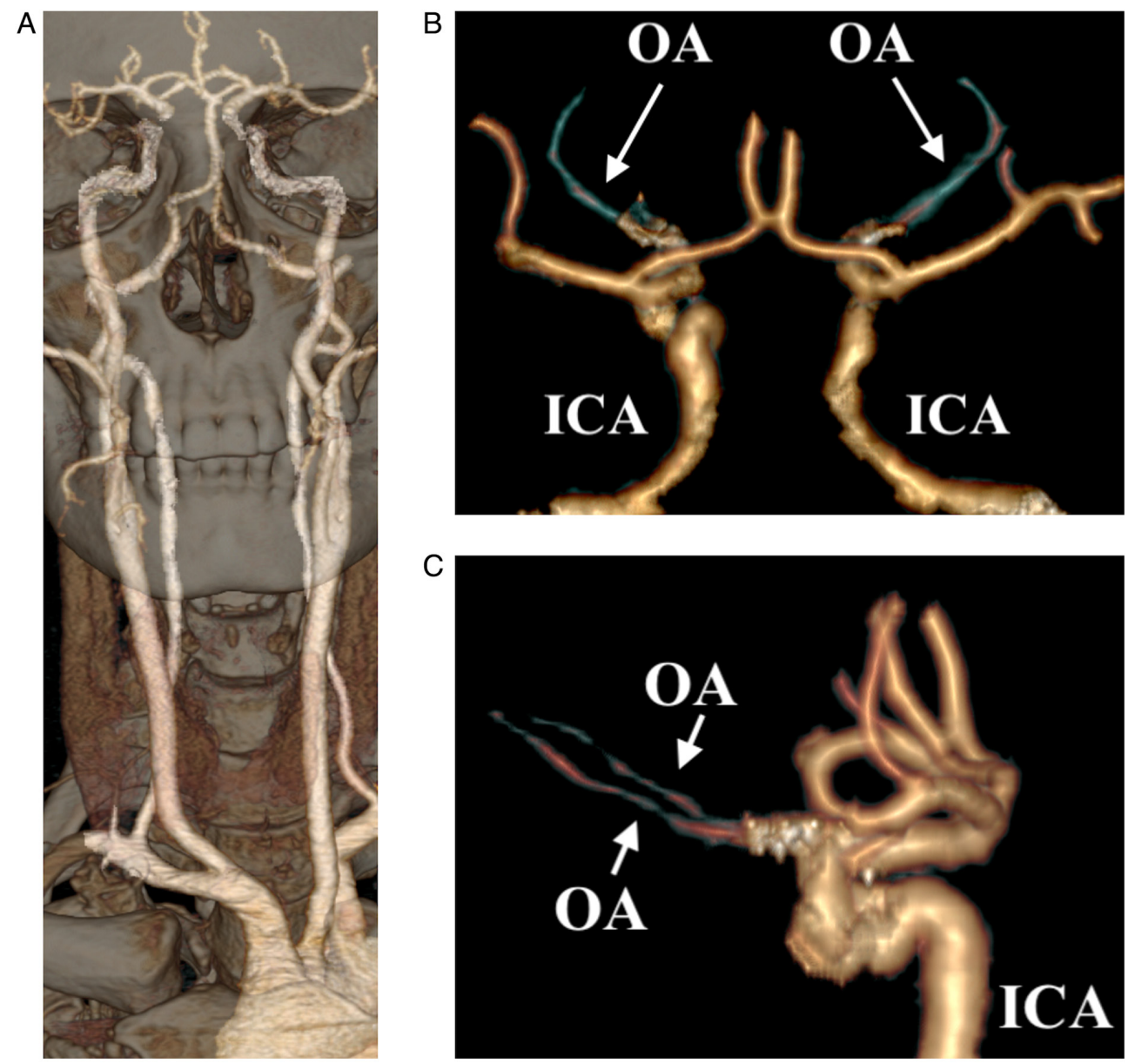

Figure 1. The VRT technique. VRT revealing the entire carotid arterial axis with (A) bone interpolation, highlighting the OA (arrow) in (B) posteroanterior view and (C) lateral plane. VRT, volume-rendered technique; OA, ophthalmic artery; ICA, internal carotid artery.
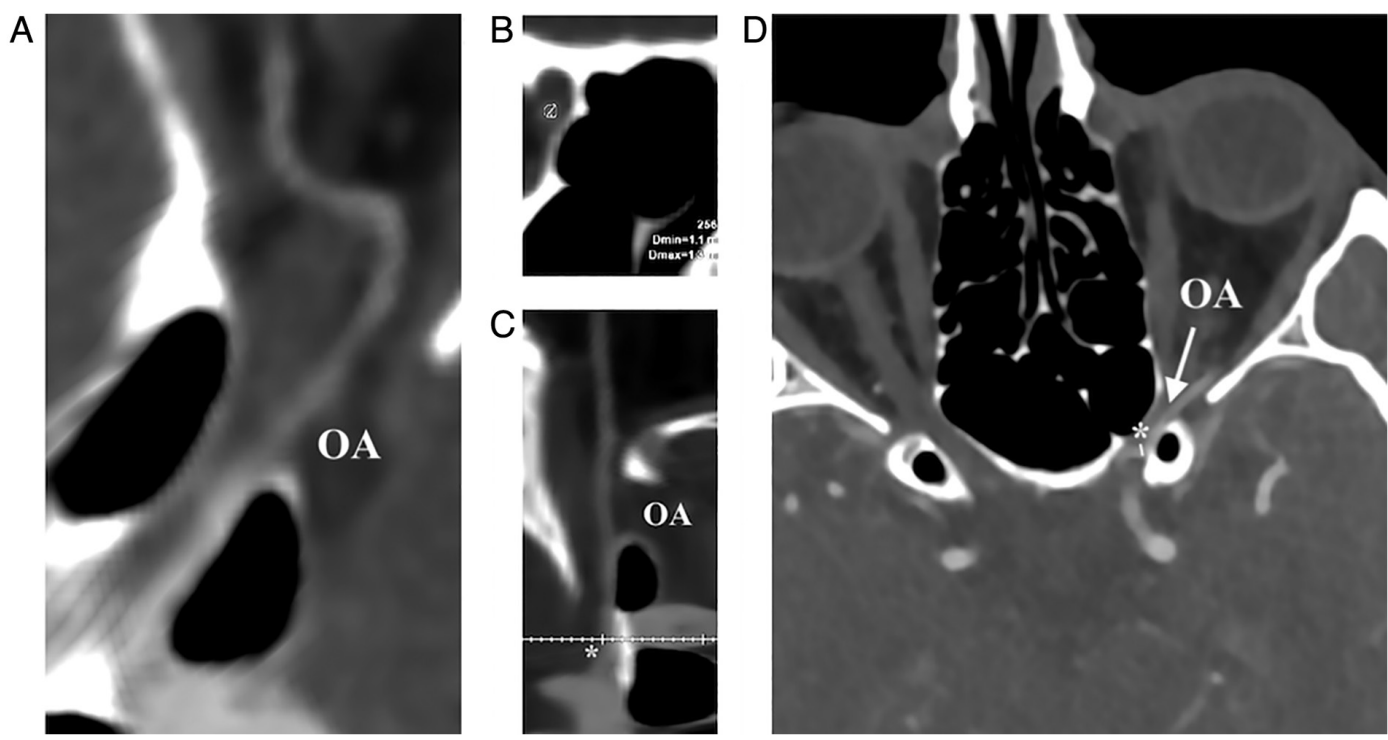

Figure 2. Curved multiplanar reconstruction images displaying the ICA and the OA. (A) Curved multiplanar reconstruction image shows the OA through the optic canal, between the clinoid process and the sphenoid sinus. (B) The specific oblique section image with automatic measurement of the OA at the point of interest. (C) The lumen image viewing the segment between the ICA and the OA, the lineation (*) marks the position of the region of interest. (D) Familiar axial plane revealing the OA and its region of interest. OA, ophthalmic artery; ICA, internal carotid artery.

obtained and on the left side of $1.33 \mathrm{~mm}( \pm 0.2)$. By contrast, for males, the results showed a values for the OA diameter on the right side of $1.43 \mathrm{~mm}( \pm 0.24)$ and the left $1.43 \mathrm{~mm}$ $( \pm 0.26)$ (Table IV). 

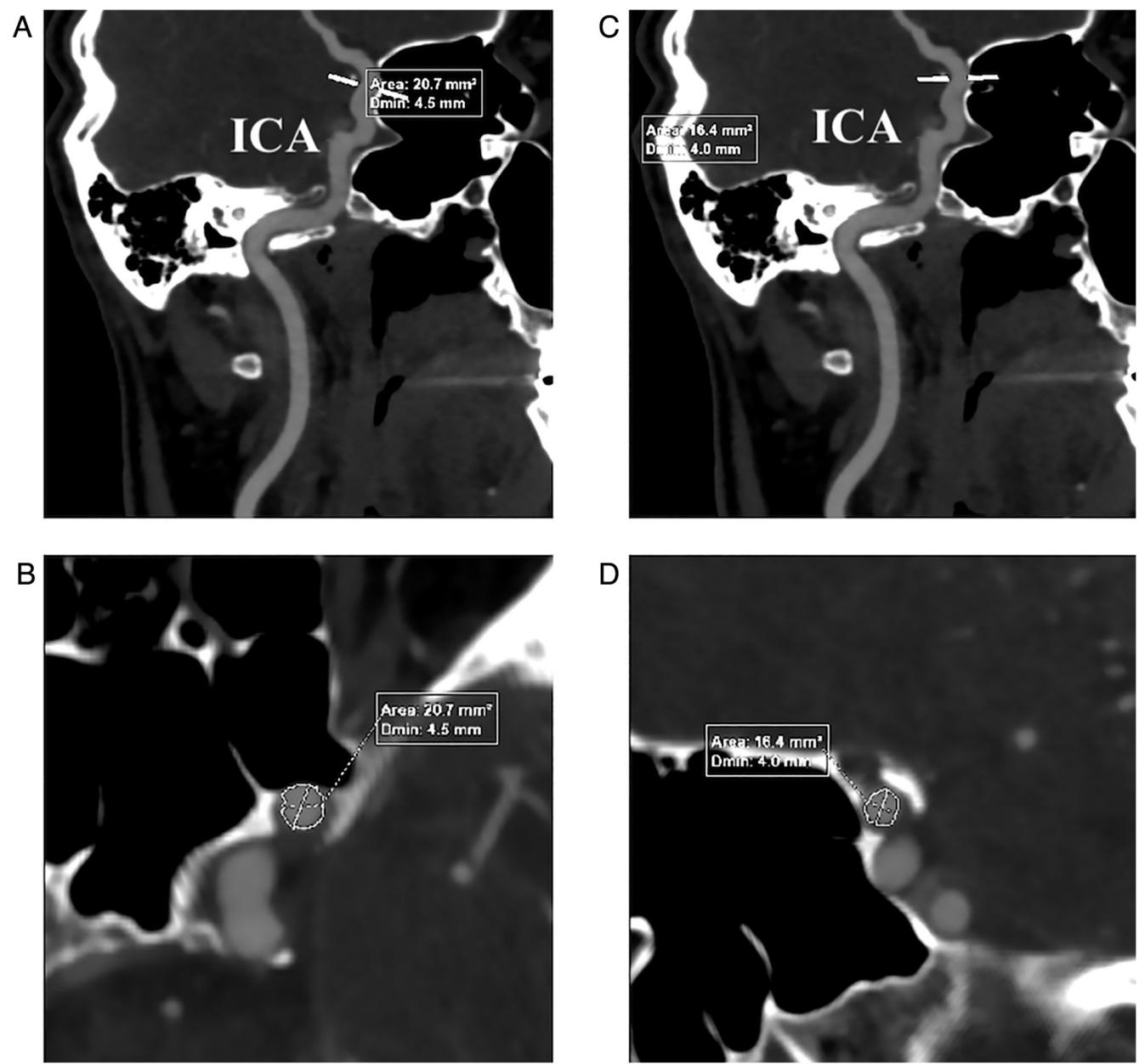

Figure 3. ICA automated measurements above (A and C) and below (B and D) the OA, rendered in curved MPR image revealing the carotid artery courses and the vascular cavity structure in a large oblique section (A and C), also in transversal planes (B and D). MPR, multiplanar reconstruction; OA, ophthalmic artery; ICA, internal carotid artery.
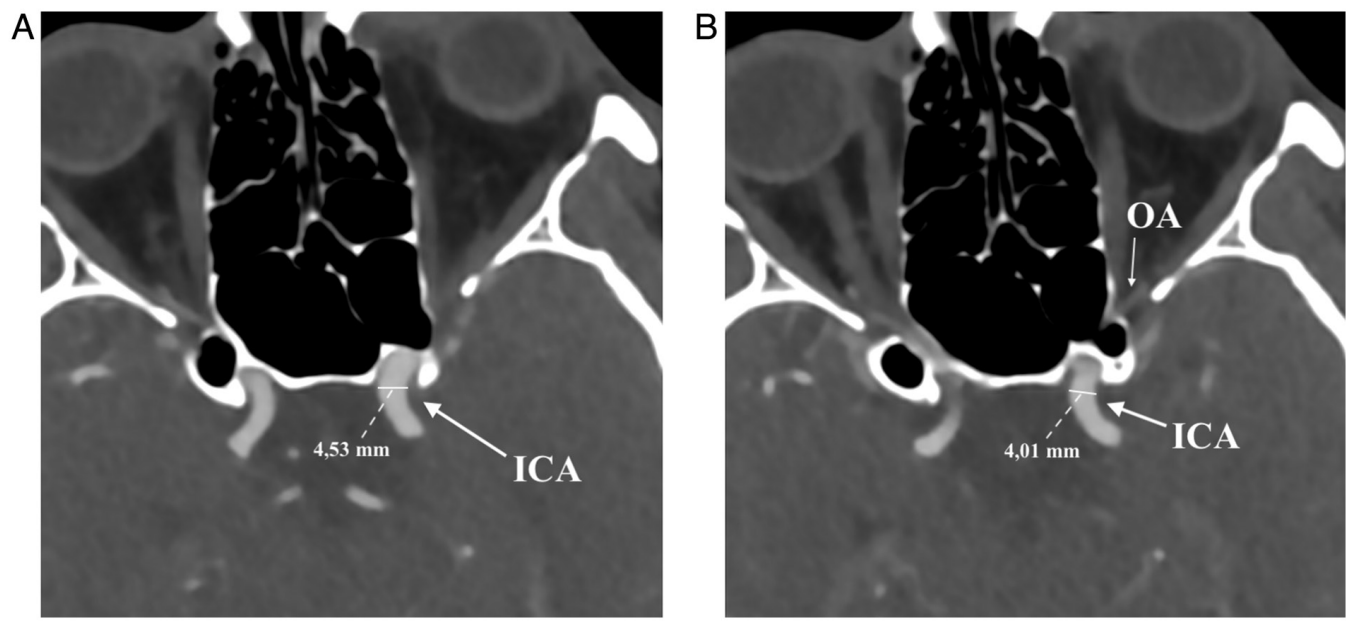

Figure 4. Axial CTA images highlighting the ICA (bold arrow) (A) before and (B) after the OA emergence with the OA passing through the optic canal. CTA, computed tomography angiography; OA, ophthalmic artery; ICA, internal carotid artery.

OA caliber and age. The study group was then subdivided into age groups, analyzing the average diameter of OA for each subgroup, as follows: for the subgroup $<40$ years, a value of $1.28 \mathrm{~mm}( \pm 0.21)$ was obtained, between 40 and 49 years a value of $1.34 \mathrm{~mm}( \pm 0.26)$, between 50 and 59 years a value of
$1.37 \mathrm{~mm}( \pm 0.23)$, between 60 and 69 years a value of $1.42 \mathrm{~mm}$ $( \pm 0.23)$ and in the group 70-79 years a value of $1.37 \mathrm{~mm}$ ( \pm 0.23$)$ (Fig. 5).

An ANOVA test was used to verify whether there were statistically significant differences between age groups. The 
Table I. OA caliber.

\begin{tabular}{lcrr}
\hline Variable & OA diameter $(\mathrm{mm})$ & Right OA diameter $(\mathrm{mm})$ & Left OA diameter $(\mathrm{mm})$ \\
\hline Mean \pm SD & $1.38 \pm 0.23$ & $1.38 \pm 0.24$ & $1.38 \pm 0.23$ \\
Median (IQR) & $1.35(0.37)$ & $1.37(0.38)$ & $1.37(0.34)$ \\
Min-Max (range) & $1.02-1.98(0.96)$ & $1.01-1.98(0.97)$ & $1.03-1.95(0.92)$ \\
\hline
\end{tabular}

OA, ophthalmic artery; SD, standard deviation; IQR, interquartile range.

Table II. OA caliber by sex.

\begin{tabular}{lcc}
\hline OA diameter $(\mathrm{mm})$ & Females $(\mathrm{n}=40)$ & Males $(\mathrm{n}=40)$ \\
\hline Mean \pm SD & $1.34 \pm 0.20$ & $1.43 \pm 0.24$ \\
Median (IQR) & $1.32(0.31)$ & $1.37(0.36)$ \\
Min-Max (range) & $1.02-1.71(0.69)$ & $1.08-1.98(0.90)$
\end{tabular}

OA, ophthalmic artery; SD, standard deviation; IQR, interquartile range.

Table III. OA mean difference by sex.

\begin{tabular}{lccc}
\hline $\begin{array}{l}\text { Mean F } \\
(\mathrm{mm})\end{array}$ & $\begin{array}{c}\text { Mean M } \\
(\mathrm{mm})\end{array}$ & P-value & $\begin{array}{c}\text { Mean difference } \\
(95 \% \mathrm{CI})\end{array}$ \\
\hline 1.34 & 1.43 & 0.0719 & $-0.09(-0.18-0.01)$ \\
\hline
\end{tabular}

OA, ophthalmic artery; F, female; M, male. CI, confidence interval.

Table IV. OA caliber sorted by side and sex.

\begin{tabular}{lcc}
\hline & rOA $(\mathrm{mm})$ & lOA $(\mathrm{mm})$ \\
\hline Male & & \\
Mean \pm SD & $1.43 \pm 0.24$ & $1.43 \pm 0.26$ \\
Median (IQR) & $1.44(0.33)$ & $1.39(0.41)$ \\
Min-Max (range) & $1.08-1.98(0.90)$ & $1.06-1.95(0.89)$ \\
Female & & \\
Mean \pm SD & $1.32 \pm 0.22$ & $1.33 \pm 0.2$ \\
Median (IQR) & $1.3(0.34)$ & $1.32(0.3)$ \\
Min-Max (range) & $1.01-1.76(0.75)$ & $1.03-1.77(0.74)$ \\
\hline
\end{tabular}

rOA, right ophthalmic artery; 1OA, left ophthalmic artery; SD, standard deviation; IQR, interquartile range.

results of the ANOVA test showed that the differences were not statistically significant $(\mathrm{F}=0.68$, degrees of freedom $=4,74$; $\mathrm{P}=0.6020)$. The average age was 59.72 years $( \pm 0.23)$ in the studied group with a median of 63 years and minimum and maximum values between 22 and 80 years. The global distribution was deviated to the left, with a negative skewness, and patients under the age of 35 were outliers.
The measurements on the ICA were performed on the same samples, according to the previously described method. Diameter variations of the ICA below and above the OA emergence were analyzed, resulting in an average ICA value below the OA of $4.19 \mathrm{~mm}( \pm 0.49)$ with a median of $4.12 \mathrm{~mm}$ and, above the OA of $2.84 \mathrm{~mm}( \pm 0.43)$ with a median of $2.79 \mathrm{~mm}$, with an average decrease of the caliber of $1.37 \mathrm{~mm}( \pm 0.46)$ with a median of $1.38 \mathrm{~mm}( \pm 0.675)$ (Table V).

Average values. The data analysis on the female patients revealed the mean average values for the ICA below OA of $4.05 \mathrm{~mm}( \pm 0.42)$ with a median of $3.96 \mathrm{~mm}$, while above the OA the average diameter was $2.85 \mathrm{~mm}( \pm 0.4)$ with a median of $2.81 \mathrm{~mm}$ and an average decrease of the caliber of $1.20 \mathrm{~mm}$. For males, we found mean ICA values below the OA of an average of $4.35 \mathrm{~mm}( \pm 0.44)$ with a median of $4.31 \mathrm{~mm}$ and ICA values above the OA of $2.82 \mathrm{~mm}( \pm 0.46)$, with a median of $2.79 \mathrm{~mm}$ and an average decrease in caliber of $1.53 \mathrm{~mm}$. By comparing the values, in females, the average ICA measurement below the OA was lower compared to ICA below the OA in men, but the ICA measurement above the OA in women had higher minimal values than in men, thus revealing a less steep narrowing of the ICA (Table VI).

The group was divided as per sex for a more detailed study and the ICA diameter below and above the OA emergence was analyzed according to laterality for each group. In the male group, on the left side, average dimensional values of ICA below the OA of $4.39 \mathrm{~mm}( \pm 0.5)$ with a median value of $4.32 \mathrm{~mm}$ were identified and above the OA of $2.80 \mathrm{~mm}( \pm 0.51)$ with a median of $2.79 \mathrm{~mm}$, therefore noting an average caliber decrease of $1.58 \mathrm{~mm}$. On the right side, the dimension of ICA below the OA was $4.33 \mathrm{~mm}( \pm 0.38)$ with a median value of $4.29 \mathrm{~mm}$, and the value for ICA above the OA were $2.84 \mathrm{~mm}$ $( \pm 0.41)$ with a median of $2.78 \mathrm{~mm}$, observing a decrease in caliber of $1.49 \mathrm{~mm}$ (Table VI).

Analyzing the values obtained in the male group, on the left side higher values of the ICA diameter below the OA were identified, while the ICA values above the OA were higher on the right side. In the female group, the left side average dimensional value of the ICA below the OA of $4.11 \mathrm{~mm}$ $( \pm 0.45)$ with a median value of $4.04 \mathrm{~mm}$ were observed and the value of the ICA above the OA of $2.87 \mathrm{~mm}( \pm 0.4)$ with a median of $2.87 \mathrm{~mm}$ were noted, observing a decrease in the average caliber of $1.24 \mathrm{~mm}$. Analyzing the average values for the right side, we found the ICA diameter below the OA of $3.98 \mathrm{~mm}( \pm 0.4)$ with a median value of $3.91 \mathrm{~mm}$ and above the OA of $2.83 \mathrm{~mm}( \pm 0.39)$ with a median of $2.78 \mathrm{~mm}$, observing a decrease in the average caliber of $1.15 \mathrm{~mm}$. 


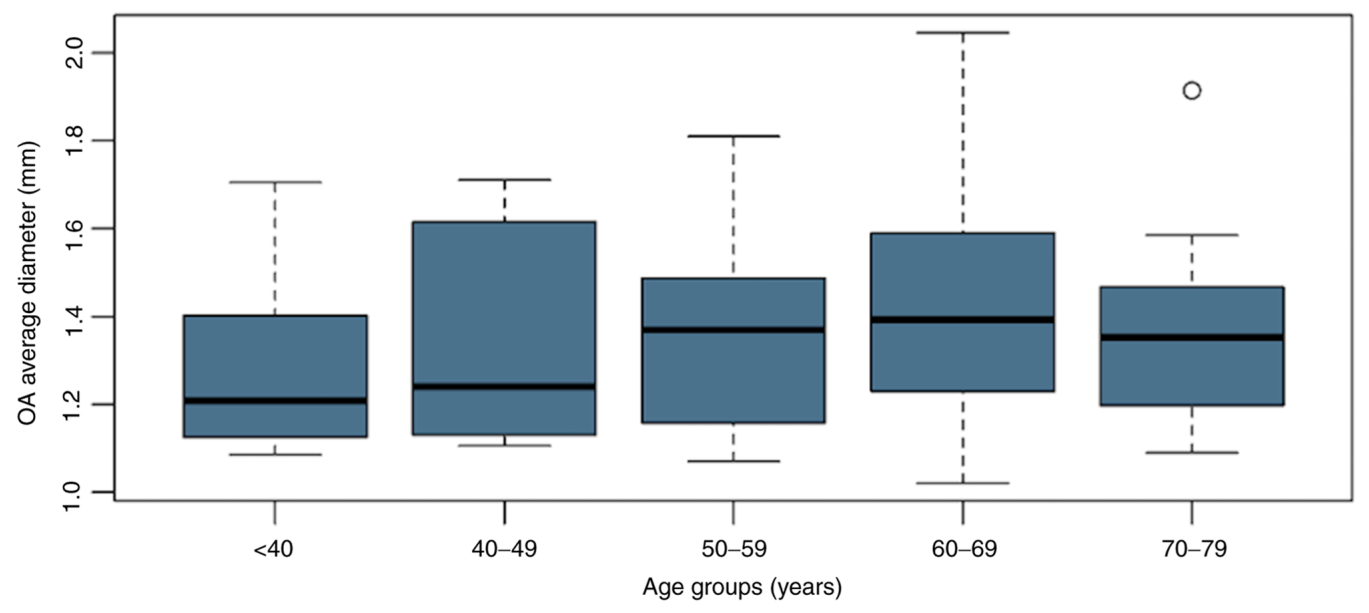

Figure 5. Histogram revealing OA average diameter between different age groups.

Assessing the values obtained from both groups, slightly higher values were observed on the left side regarding ICA diameter below the OA, while ICA values above the OA were higher on the left side in the female group, whereas for the male group the dimensions were slightly increased on the right side.

The result of the point biserial correlation coefficient test $(r=0.33)$ applied to our two variables: sex and laterality. No significant correlation was found between these two variables, although slight differences in caliber between sexes and both sides were evident.

\section{Discussion}

The OA arises from the medial ICA of the anterior clinoid process (18) and in more than $90 \%$ of cases, the OA is the first branch of the intradural C6 segment $(19,20)$. On its anatomical trajectory, it travels inferior to the optic nerve in the optic canal. In the orbit, it bypasses the lateral face of the posterior optic nerve of the ciliary ganglion, then its superior face and has triads between the superior oblique and medial right muscles, displaying an anterior trajectory forward under the superior oblique muscle. It ends in the medial angle of the eye with the dorsal arteries of the nose and the supratrochlear artery. Anatomic variants are described, such as emergence from the middle meningeal artery of a very small percentage, or trajectory that courses inferior to the optic nerve, in $10 \%$ of cases (18).

OA gives rise to multiple fine collateral branches and these can be grouped into 3 categories: i) arteries of the first group emerge inferior and external to the optic nerve; ii) arteries of the second group detach above the optic nerve; iii) arteries of the third group formed medially by the optic nerve, along the medial wall of the optic cavity (21).

The $\mathrm{OA}$ is a natural source of direct anastomoses with the external carotid artery (ECA) through its multiple collateral vessels $(22,23)$. Known anastomoses between branches of $\mathrm{OA}$ and the external carotid artery are found between the lacrimal artery and the anterior branch of the middle meningeal artery, progressing through the superior orbital fissure or the tympanomeningeal fissure $(24,25)$. Additionally, there are more anastomoses between the lacrimal artery and the deep temporal, transverse facial, and orbitozygomatic infraorbital arteries $(26,27)$. Other ICA-ECA links are known to be found between the dorsal nasal artery and the facial artery or infraorbital artery and, rarely, between the supratrochlear branches and the frontal branches of the superficial temporal artery $(22,27)$.

Thorough knowledge of the microsurgical anatomy of the $\mathrm{OA}$, the appearance of its branches, and its anastomoses with the carotid system are critical to proceed with safe and effective endovascular and other surgical procedures involving this vascular area $(22,25)$. In the current study, an OA diameter was identified that varies between 1.02 and $1.98 \mathrm{~mm}$, with an average of $1.38 \mathrm{~mm}$, while other specialized studies (angiographic/cadaveric) reported variability of the OA diameter between 0.7 and $1.4 \mathrm{~mm}(1)$, an average value of its original diameter of $1.6 \mathrm{~mm}$, with a range of 1.5-1.8 $\mathrm{mm}$ (25), or a mean average of $1.50 \mathrm{~mm}(28,29)$.

Regarding the analysis of the sex-related results of the present study, a slight difference between the OA dimensions was recorded, namely the OA diameter in women was smaller than that in men. The data, supported by specialized studies where the numerical values vary, but the ratio is maintained, showed a difference in size, in favor of males. Literature studies have reported OA values for males of $1.54 \mathrm{~mm}$ (9) or $1.37 \mathrm{~mm}$ (28), while for females, the values reach $1.31 \mathrm{~mm}$ (9) and $1.35 \mathrm{~mm}$, respectively (30).

Results similar to the current study regarding sex-related differences of the average volumes of the OA caliber were also reported by other studies that also admit that there is no statistically significant difference between OA diameters depending on sex, despite minor variations in caliber (30).

We did not find a certain dominant side regarding the OA caliber, as values between the left side and the right side varied by less than $0.1 \mathrm{~mm}$, as indicated by other authors $(29,31)$.

The proximal and distal ICA caliber of the OA emergence was measured, with values of 4.19 and $2.84 \mathrm{~mm}$, respectively, and caliber variations of $1.37 \mathrm{~mm}$. Our obtained mean values are approximately $2 \mathrm{~mm}$ smaller than those found by Jiménez-Castellanos et al in their cadaveric study, reporting values of ICA diameter below OA origin at $7.01 \pm 0.92 \mathrm{~mm}$, and of $5.19 \pm 1.08 \mathrm{~mm}$ above the OA origin (29). 
Table V. ICA caliber before and after OA origin.

\begin{tabular}{lcrr}
\hline & ICA below OA $(\mathrm{mm})$ & ICA above OA $(\mathrm{mm})$ & Decrease in caliber $(\mathrm{mm})$ \\
\hline Mean \pm SD & $4.19 \pm 0.49$ & $2.84 \pm 0.43$ & $1.37 \pm 0.46$ \\
Median (IQR) & $4.12(0.62)$ & $2.79(0.66)$ & $1.38(0.675)$ \\
Min-Max (range) & $2.89-5.41(2.52)$ & $2.08-4.05(1.97)$ & $0.15-2.52(2.37)$ \\
\hline
\end{tabular}

ICA, internal carotid artery; OA, ophthalmic artery; SD, standard deviation; IQR, interquartile range.

Table VI. ICA caliber sorted by side and sex.

\begin{tabular}{|c|c|c|c|}
\hline & ICA below OA (mm) & ICA above OA (mm) & Decrease in caliber (mm) \\
\hline \multicolumn{4}{|l|}{ Male average } \\
\hline Mean \pm SD & $4.35 \pm 0.44$ & $2.82 \pm 0.46$ & $1.53 \pm(0.43)$ \\
\hline Median (IQR) & $4.31(0.65)$ & $2.79(0.72)$ & $1.57(0.53)$ \\
\hline Min-Max (range) & $3.35-5.39(2.04)$ & $2.08-4.05$ (1.97) & $0.46-2.52(2.04)$ \\
\hline \multicolumn{4}{|l|}{ Male left side } \\
\hline Mean \pm SD & $4.39 \pm 0.5$ & $2.80 \pm 0.51$ & $1.58 \pm 0.43$ \\
\hline Median (IQR) & $4.32(0.75)$ & $2.79(0.78)$ & $1.59(0.46)$ \\
\hline Min-Max (range) & $3.56-5.39(1.83)$ & $2.08-4.05(1.97)$ & $0.67-2.52(1.85)$ \\
\hline \multicolumn{4}{|l|}{ Male right side } \\
\hline Mean \pm SD & $4.33 \pm 0.38$ & $2.84 \pm 0.41$ & $1.49 \pm 0.44$ \\
\hline Median (IQR) & $4.29(0.6)$ & $2.78(0.63)$ & $1.57(0.59)$ \\
\hline Min-Max (range) & $3.35-5.01(1.66)$ & $2.25-3.67(1.42)$ & $0.46-2.41(1.95)$ \\
\hline \multicolumn{4}{|l|}{ Female average } \\
\hline Mean \pm SD & $4.05 \pm 0.42$ & $2.85 \pm 0.4$ & $1.20 \pm 0.43$ \\
\hline Median (IQR) & $3.96(0.51)$ & $2.81(0.62)$ & $1.17(0.57)$ \\
\hline Min-Max (range) & $3.22-5.08(1.86)$ & $2.17-3.63(1.5)$ & $0.15-2.22(2.07)$ \\
\hline \multicolumn{4}{|l|}{ Female left side } \\
\hline Mean \pm SD & $4.11 \pm 0.45$ & $2.87 \pm 0.4$ & $1.24 \pm 0.41$ \\
\hline Median (IQR) & $4.04(0.49)$ & $2.87(0.65)$ & $1.28(0.55)$ \\
\hline Min-Max (range) & $3.42-5.08(1.66)$ & $2.28-3.6(1.32)$ & $0.15-2.22(2.07)$ \\
\hline \multicolumn{4}{|l|}{ Female right side } \\
\hline Mean \pm SD & $3.98 \pm 0.4$ & $2.83 \pm 0.39$ & $1.15 \pm 0.45$ \\
\hline Median (IQR) & $3.91(0.48)$ & $2.78(0.56)$ & $1.13(0.66)$ \\
\hline Min-Max (range) & $3.22-4.94(1.72)$ & $2.17-3.63(1.5)$ & $0.43-1.98(1.55)$ \\
\hline
\end{tabular}

ICA, internal carotid artery; OA, ophthalmic artery; SD, standard deviation; IQR, interquartile range.

Regarding the variations of the ICA diameter above/below the OA emergence, in the present study values of $0.15-2.52 \mathrm{~mm}$ were found, with an average of $1.37 \pm 0.46 \mathrm{~mm}$. Sudakevitch emphasized in his study the idea that the carotid artery suffers a steep narrowing after the emergence of the OA, ranging between 2 and $3 \mathrm{~mm}$ but not more than $4 \mathrm{~mm}$ (8). In addition, other specialized studies found a narrowing of their caliber between 1 and $3 \mathrm{~mm}$ (3) or $1.6 \mathrm{~mm}$ (32).

Comparing the ICA diameter between males and females, a higher value in men was found, with a caliber narrowing of $1.53 \mathrm{~mm}$ in men compared to $1.2 \mathrm{~mm}$ in women after the emergence of $\mathrm{OA}$, the results correlating with specialized studies that also report larger sizes of the ICA in men (33-35).
However, the present study has some limitations. Besides the relatively low number of studies, only patients with a normal carotid axis were included in the study as pre-existent systemic diseases of the included patients were unknown and could impact the vascular lumen (e.g., diabetes). Another significant limitation of this study is the origin of the OA; we only included patients with the OA originating from ICA's ophthalmic segment, while different origins of the OA have been described, such as the intracavernous origin $(36,37)$, the double origin from the ICA $(26,38)$, and middle meningeal artery origin $(1,39)$, or, in some cases, with emergence from ICA but not from its C6 segment (40-42) and even from the anterior cerebral artery $(43,44)$. 
The diameter of OA and its relation to the ICA have rarely been studied in detail on CTAs, and data on this topic are scarce. Thus, the subject required thorough investigation. We aimed to analyze morphometric features of the OA, as it is the main vessel that supplies oxygenated blood to the eye. The study suggests obtaining further information on the topic aiming to improve and contribute to the knowledge of the diameters of OA and ICA above/below the emergence of the $\mathrm{OA}$, data that have an impact in various medical fields.

The present study revealed an average diameter of the OA of $1.38 \mathrm{~mm}$, with a median value of $1.35 \mathrm{~mm}$. We analyzed diameter variations of the ICA below and above the OA emergence, resulting in an average ICA value below the OA of $4.19 \mathrm{~mm}$, respectively, above the OA of $2.84 \mathrm{~mm}$, with an average decrease of the caliber of $1.37 \mathrm{~mm}$. It was observed that the results denoted a slight sex-related difference between the studied diameters and only minor differences between both sides but this did not prove to be statistically significant.

Notable non-pathological aspects and variations of the OA and the ICA must be familiar for anatomists, radiologists, and surgeons. The importance of solid knowledge of the anatomy and morphometry of the OA translates to long-term follow-up of patients at risk and to planning surgical or interventional procedures. CTA is a useful tool for monitoring the OA diameter changes in patients at risk for atherosclerotic carotid disease and could be useful in patients with other diseases that affect the small vessels. Further studies may be helpful to evaluate the applicability of CTA for timely assessment of the OA. Improved non-invasive visualization of the OA and its origin, course, and branches on CTA may aid the avoidance of invasive diagnostic methods.

\section{Acknowledgements}

Not applicable.

\section{Funding}

No funding was received.

\section{Availability of data and materials}

The datasets used and/or analyzed during the current study are available from the corresponding author on reasonable request.

\section{Authors' contributions}

RAB conceived the presented idea and took lead in writing the manuscript. SJ developed the theory. RAB, CS, RB performed the image analysis. RC, and SJ helped supervise the project. $\mathrm{RB}$ was in charge of overall direction and planning. RAB and RB authenticate the data in this study. All authors read and approved the final manuscript.

\section{Ethics approval and consent to participate}

All procedures performed in the studies involving human participants were in accordance with the ethical standards of the Ethics Committee of 'Sf. Apostol Andrei' County Hospital
(34490/08.08.2019) and with the 1964 Helsinki Declaration and its later amendments or comparable ethical standards.

\section{Patient consent for publication}

Informed consent was obtained from all participants included in the study.

\section{Competing interests}

The authors declare that they have no competing interests.

\section{References}

1. Hayreh SS and Dass R: The ophthalmic artery: I: Origin and intra-cranial and intra-canalicular course. $\mathrm{Br} \mathrm{J}$ Ophthalmol 46: 65-89, 1962.

2. Jurja S, Coman M and Hîncu M: The ultraviolet influence upon soft tissues. Rom J Morphol Embriol 58: 45-52, 2017.

3. Jurja S, Hîncu M, Dobrescu MA, Golu AE, Bălăşoiu AT and Coman M: Ocular cells and light: Harmony or conflict? Rom J Morphol Embriol 55: 257-261, 2014.

4. Hayreh SS: The ophthalmic artery: III: Branches. $\mathrm{Br}$ J Ophthalmol 46: 212-247, 1962.

5. Hayreh SS and Dass R: The ophthalmic artery: II. Intra-orbital course. Br J Ophthalmol 46: 165-185, 1962.

6. Bouthillier A, van Loveren HR and Keller JT: Segments of the internal carotid artery: A new classification. Neurosurgery 38: 425-433, 1996

7. Michalinos A, Zogana S, Kotsiomitis E, Mazarakis A and Troupis T: Anatomy of the ophthalmic artery: A review concerning its modern surgical and clinical applications. Anat Res Int 2015: 591961, 2015.

8. Sudakevitch T: The variations in the system of trunks of the posterior ciliary arteries. Br J Ophthalmol 31: 738-760, 1947.

9. Erdogmus S and Govsa F: Anatomic features of the intracranial and intracanalicular portions of ophthalmic artery: For the surgical procedures. Neurosurg Rev 29: 213-218, 2006.

10. Kuru Y: Meningeal branches of the ophthalmic artery. Acta Radiol Diagn (Stockh) 6: 241-251, 1967.

11. Lang $\mathbf{J}$ and Kageyama I: The ophthalmic artery and its branches, measurements and clinical importance. Surg Radiol Anat 12: 83-90, 1990.

12. Vignaud J, Hasso AN, Lasjaunias P and Clay C: Orbital vascular anatomy and embryology. Radiology 111: 617-626, 1974.

13. Lasjaunias P, Brismar J, Moret $\mathbf{J}$ and Théron J: Recurrent cavernous branches of the ophthalmic artery. Acta Radiol Diagn (Stockh) 19: 553-560, 1978.

14. Shimada K, Kaneko Y, Sato I, Ezure H and Murakami G: Classification of the ophthalmic artery that arises from the middle meningeal artery in Japanese adults. Okajimas Folia Anat Jpn 72: 163-176, 1995

15. Hankey GJ, Warlow CP and Sellar RJ: Cerebral angiographic risk in mild cerebrovascular disease. Stroke 21: 209-222, 1990.

16. Lian K, White JH, Bartlett ES, Bharatha A, Aviv RI, Fox AJ and Symons SP: NASCET percent stenosis semi-automated versus manual measurement on CTA. Can J Neurol Sci 39: 343-346, 2012.

17. Baz RO, Scheau C, Baz RA and Niscoveanu C: Buhler's arc: An unexpected finding in a case of chronic abdominal pain. J Gastrointestin Liver Dis 29: 304, 2020.

18. Hayreh S: Orbital vascular anatomy. Eye 20: 1130-1144, 2006.

19. Picard L, Vignaud J, Lombardi G and Roland J: Radiological anatomy of the origin of the ophthalmic artery. Mod Probl Ophthalmol 14: 164-169, 1975.

20. Kyoshima K, Oikawa S and Kobayashi S: Interdural origin of the ophthalmic artery at the dural ring of the internal carotid artery. Report of two cases. J Neurosurg 92: 488-489, 2000.

21. Huynh-Le P, Natori Y and Sasaki T: Surgical anatomy of the ophthalmic artery: Its origin and proximal course. Neurosurgery 57 (Suppl 4): S236-S241, 2005.

22. Geibprasert S, Pongpech S, Armstrong D and Krings T: Dangerous extracranial-intracranial anastomoses and supply to the cranial nerves: Vessels the neurointerventionalist needs to know. Am J Neuroradiol 30: 1459-1468, 2009. 
23. Bonasia S, Bojanowski M and Robert T: Embryology and anatomical variations of the ophthalmic artery. Neuroradiology 62: 139-152, 2020

24. Moret J, Lasjaunias P, Théron $\mathrm{J}$ and Merland JJ: The middle meningeal artery. Its contribution to the vascularisation of the orbit. J Neuroradiol 4: 225-248, 1977 (In English, French).

25. Perrini P, Cardia A, Fraser K and Lanzino G: A microsurgical study of the anatomy and course of the ophthalmic artery and its possibly dangerous anastomoses. J Neurosurg 106: 142-150, 2007.

26. Bertelli E, Regoli M and Bracco S: An update on the variations of the orbital blood supply and hemodynamic. Surg Radiol Anat 39: 485-496, 2017.

27. Bossi R and Pisani C: Collateral cerebral circulation through the ophthalmic artery and its efficiency in internal carotid occlusion. Br J Radiol 28: 462-469, 1955.

28. Whitnall SE: The anatomy of the human orbit and accessory organs of vision. Humphrey Milford, Oxford University Press, London, 1932.

29. Jiménez-Castellanos J, Carmona A, Castellanos L and CatalinaHerrera CJ: Microsurgical anatomy of the human ophthalmic artery: A mesoscopic study of its origin, course and collateral branches. Surg Radiol Anat 17: 139-143, 1995 (In English, French).

30. Zhang T, Fan S, He W, Zhang T and Wang Y: Ophthalmic artery visualization and morphometry by computed tomography angiography. Graefes Arch Clin Exp Ophthalmol 253: 627-631, 2015.

31. Govsa F, Erturk M, Kayalioglu G, Pinar Y, Ozer MA and Ozgur T: Neuro-arterial relations in the region of the optic canal Surg Radiol Anat 21: 329-335, 1999.

32. Wolff E: The anatomy of the eye and orbit: Including the central connections, development and comparative anatomy of the visual apparatus. Nature 132: 767, 1933

33. Harmon L and Boccalandro F: Comparison of carotid artery dimensions and lesion length measured by B-mode ultrasonography and quantitative angiography in patients with severe stenosis undergoing percutaneous revascularization. J Clin Ultrasound 42: 270-276, 2014.

34. Krejza J, Arkuszewski M, Kasner SE, Weigele J, Ustymowicz A, Hurst RW, Cucchiara BL and Messe SR: Carotid artery diameter in men and women and the relation to body and neck size. Stroke 37: 1103-1105, 2006.
35. Gabrielsen TO and Greitz T: Normal size of the internal carotid, middle cerebral and anterior cerebral arteries. Acta Radiol Diagn (Stockh) 10: 1-10, 1970

36. Dilenge D and Ascherl GF Jr: Variations of the ophthalmic and middle meningeal arteries: Relation to the embryonic stapedial artery. AJNR Am J Neuroradiol 1: 45-54, 1980

37. Lasjaunias P, Moret J, Manelfe C, Théron J, Hasso T and Seeger J: Arterial anomalies at the base of the skull. Neuroradiology 13: 267-272, 1977.

38. Curnow J: Two instances of irregular ophthalmic and middle meningeal arteries. J Anat Physiol 8 (Pt 1): 155-156, 1873.

39. Parlato C, di Nuzzo G, Luongo M, Tortora F and Briganti F: Anatomical variant of origin of ophthalmic artery: Case report. Surg Radiol Anat 33: 275-278, 2011.

40. Toma N: Anatomy of the ophthalmic artery: Embryological consideration. Neurol Med Chir (Tokyo) 56: 585-591, 2016.

41. Hamada J, Kitamura I, Kurino M, Sueyoshi N, Uemura S and Ushio Y: Abnormal origin of bilateral ophthalmic arteries. Case report. J Neurosurg 74: 287-289, 1991.

42. Baltsavias G, Türk Y and Valavanis A: Persistent ventral ophthalmic artery associated with supraclinoid internal carotid artery aneurysm: Case report and review of the literature. J Neuroradiol 39: 186-189, 2012.

43. Islak C, Ogüt G, Numan F, Cokyüksel O and Kuday C: Persistent nonmigrated ventral primitive ophthalmic artery. Report on one case. J Neuroradiol 21: 46-49, 1994 (In English, French).

44. Li Y, Horiuchi T, Yako T, Ishizaka S and Hongo K: Anomalous origin of the ophthalmic artery from the anterior cerebral artery. Neurol Med Chir (Tokyo) 51: 579-581, 2011.

This work is licensed under a Creative Commons Attribution-NonCommercial-NoDerivatives 4.0 International (CC BY-NC-ND 4.0) License. 